\title{
SOBRE EL VACIADO DORSAL DE LA DAMA DE ELCHE: OTRA OBSERVACIÓN
}

\author{
ABOUT THE DORSAL EMPTY CAVITIES OF THE DAMA DE ELCHE: ANOTHER OBSERVATION
}

RAFAEL RAMOS FERNÁNDEZ

Museo Arqueológico y de Historia de Elche «Alejandro Ramos Folqués»

La Dama de Elche (Fig. 1) es un busto esculpido en piedra caliza procedente, igual que las demás piezas del conjunto escultórico ibérico de La Alcudia, de las canteras ilicitanas existentes en la Sierra Peligros, en la partida de Ferriol, por lo que su producción fue local. En el momento de su hallazgo todavía conservaba restos de la pintura que la decoró, perceptible tanto en los labios, rojos, como en sus vestiduras: en la túnica interior azul, en la mantilla roja, montada sobre la especie de tiara que cubre su cabeza, y en el manto marrón con ribete rojo. Policromía que, atenuada, todavía conserva según se desprende de los pertinentes análisis de pigmentación realizados (Luxán, Prada y Dorrego, 2005, 422-423).

Es probable que la concepción del busto respondiera a una forma religiosa cuya difusión se realizara a través del mundo mediterráneo grequizado, una forma que se pudo extender a las representaciones de ciertas divinidades subterráneas del occidente mediterráneo: itálicas, etruscas, púnicas e ibéricas. De ser así, el busto pudo ser una representación simbólica en la que lo realmente importante era el significado, no la figuración, puesto que se mostraría alegóricamente cortado del resto de su cuerpo. En función de esta posibilidad la elaboración de bustos pudo presuponer la necesidad de introducir en el pensamiento de los artesanos griegos, y consecuentemente más tarde en el de los íberos, aquella forma simbólica con la finalidad de transmitir de modo visible el carácter fúnebre de las divinidades así representadas, que precisamente por responder a dicha forma constituirían manifestaciones expresivas de sus epifanías ante los humanos (Ramos Fernández, 1996, 285).

Pero ila Dama de Elche que nosotros vemos hoy fue concebida como busto? (Paris, 1910, 95) o ¿fue convertida en busto en una etapa cronológica posterior a la de su creación, coincidente con el inicio de la época helenística? Tal posibilidad iría vinculada a la supuesta separación del busto de una estatua completa de mujer (Bendala, 1994, 91-92; 1996, 301;1997, 144; Bendala-Blánquez, 1997, 139; Ramos-Bendala, 1997,
248-249; Blánquez-Comas, 1999, 238), sentada en un trono, obra similar a la que se conserva en el Museo Monográfico de La Alcudia (Ramos Fernández, 2003, 379-408; Ramos Molina, 1999, III 203-206).

La conversión en busto implicaría posiblemente la divinización de la imagen, puesto que así aquella representación incompleta expresaría su potestad de traspasar los pisos del universo, pues tal vez la iconografía ibérica, al igual que lo hizo la helénica (Berard, 1974, 22), utilizara la imagen incompleta para precisar en sus representaciones la diferencia entre las divinidades y los humanos.

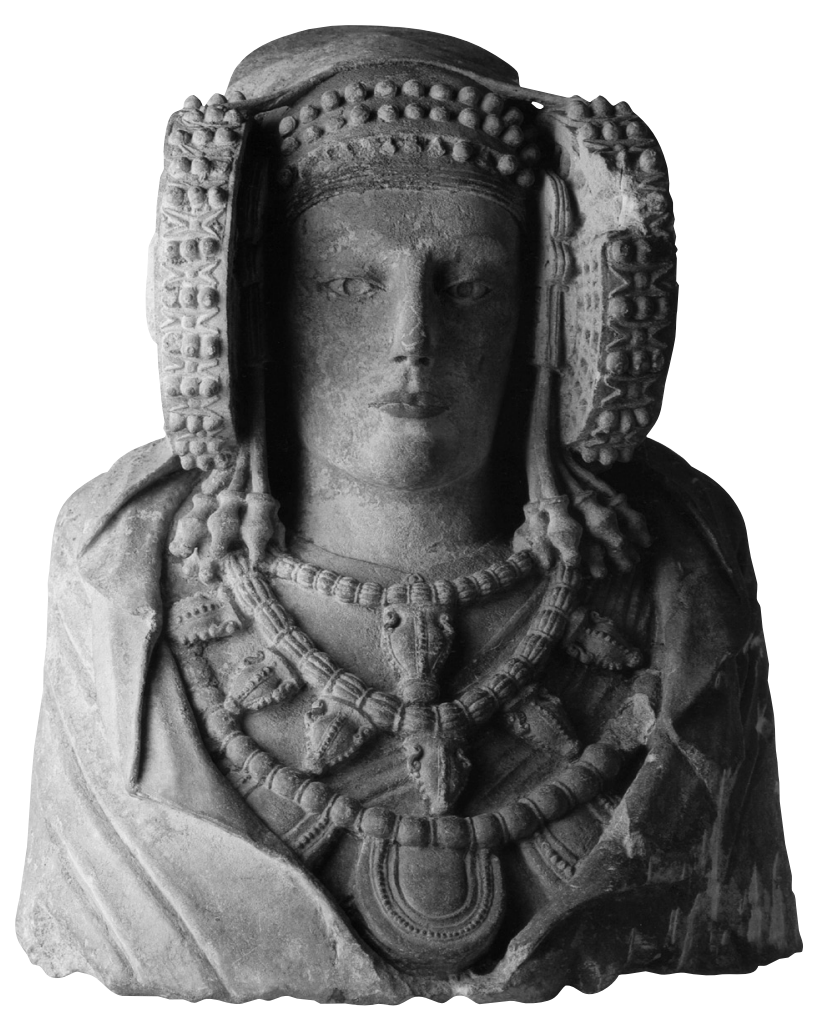

Figura 1: Dama de Elche 


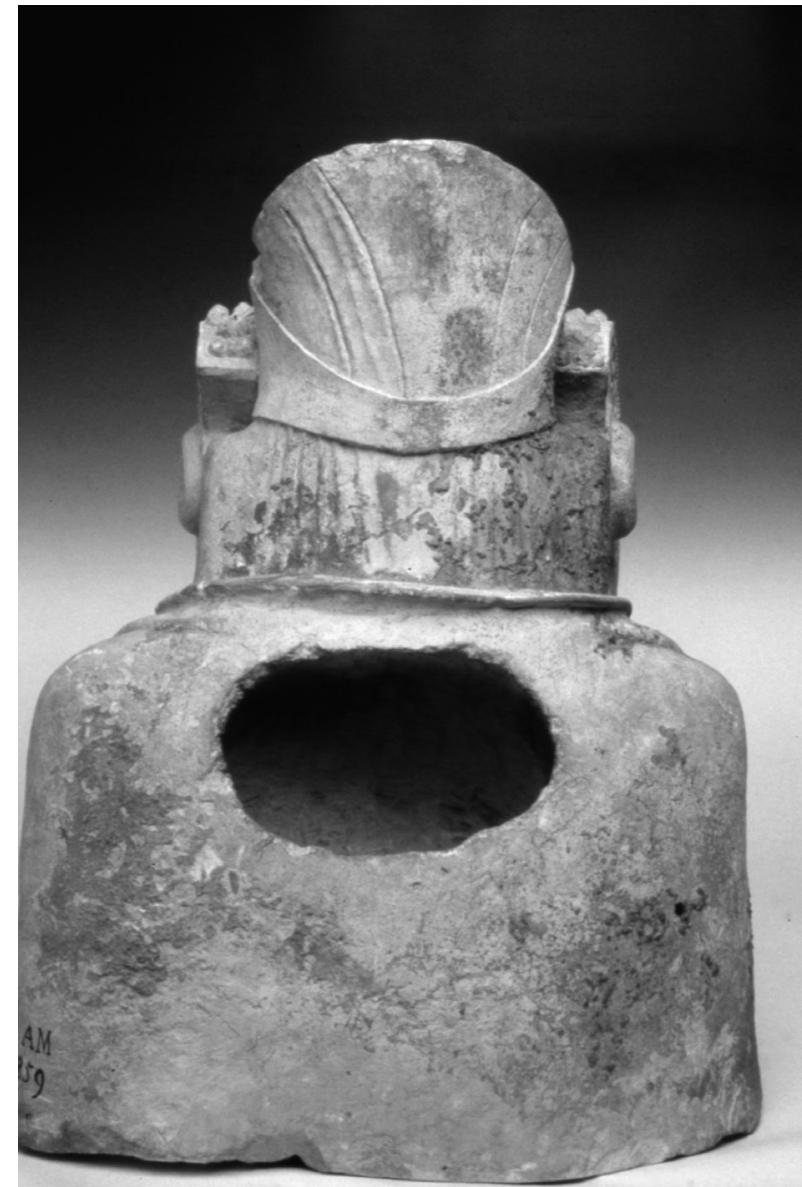

Figura 2: Aspecto dorsal de la Dama de Elche.

La Dama de Elche presenta un acabado tosco en su espalda que contrasta con el de su zona frontal y especialmente con el pulido de su rostro (Figs. 2 y 3 ). En ella tiene un hueco o cavidad casi esférica de dieciocho centímetros de diámetro y dieciseis de profundidad, cuya misión o finalidad ha sido objeto de muy distintas interpretaciones. Se escribió (Ibarra Ruiz, 1897; 1903; 1926, 186-213) que el hueco fue hecho a propósito para que sirviera de resonante tornavoz al sacerdote que oculto tras denso velo daría enigmáticas respuestas a las preguntas de los que, ansiosos, deseaban conocer anticipadamente una contestación a sus deseos, y que dicha cavidad era excesivamente grande para asilar un simple grapón y que, en ella, eran de observar tres caracteres: primero, la forma de bola que adoptaba; segundo, lo liso de la pared interna, que no conservaba el más ligero vestigio de yeso, cal, etc.; y tercero, la delgadez de la pared que formaba la espalda. Y se decía que en aquel hueco resonaba la voz humana como si aquel fuera una pequeña tinaja.

Además se había creído (Mélida, 1897a, 427; 1897b, 440 y 1898) que sirvió para sujetar con algún hierro la estatua, pues ésta, como las del Cerro de los Santos, tiene la espalda sin acabar de labrar, lo que parecía probar que se había destinado para ser colocada contra un muro.

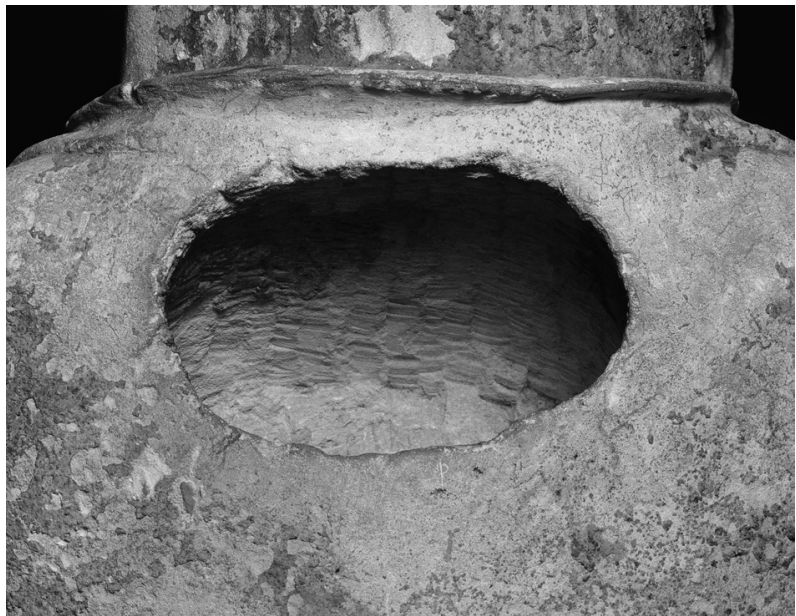

Figura 3: Detalle de la cavidad de la Dama de Elche.

Y también se informó (Hübner, 1898, 114-134) que probablemente serviría para la introducción en él de un garfio que la sujetara al muro sobre el que fuera apoyada, después de ser colocada en un alto basamento; y que este hueco hubiera servido para encerrar las cenizas de algún muerto, aunque ello no era más que una suposición que tendría algún fundamento si el busto se hubiese encontrado o hubiera pertenecido a una tumba.

Hubo quien opinó (Paris, 1898, 1-32) que el trabajo del busto, que por la espalda está ejecutado rápidamente, con una cavidad regular, no podía ser un agujero para empotramiento. Era, por decirlo así, un depósito de ofrendas y ello era suficiente para fijar netamente el carácter votivo o funerario de la figura.

Aunque la opinión generalizada hasta nuestros días ha sido la referida a su condición de urna cineraria, opinión que como ya ha sido indicado alude a que esta cavidad estuvo destinada a contener los restos de la cremación de un cadáver, es decir a su funcionalidad funeraria, La Alcudia de las épocas ibéricas no albergó ninguna necrópolis sino una ciudad.

$\mathrm{Al}$ respecto parece evidente también que la capacidad de este vaciado es insuficiente para considerarlo como una urna funeraria y que sólo sería válido como depósito de alguna ofrenda o contenedor de algún objeto talismánico que conferiría al busto el carácter de relicario. Esta insuficiente incapacidad aparente $\left(2.571 \mathrm{~cm}^{3}\right)$ se manifiesta (Ramos Fernández, 1987a, 94-105; 1991, 116-119) al intentar compararla con la que ofrece la Dama de Baza $\left(9.316 \mathrm{~cm}^{3}\right)$, que no tiene la cavidad en la espalda de la imagen sino que aquella fue realizada en un lateral de su trono, en el que ocupa buena parte de su zona baja (Presedo, 1973, 44), en el que se depositaron los restos de la cremación de un difunto (Reverte, 1986, 187-192) (Figs. 3, 4 y 7); y se manifiesta más aún, en el mismo Elche, al hacerlo con el busto de guerrero de El Parque (Ramos Fernández, 1987b, 681-699; 1990, 26-34; Ramos Fernández y Ramos Molina, 1992, 42-44) (Fig. 6), cuyo vaciado 


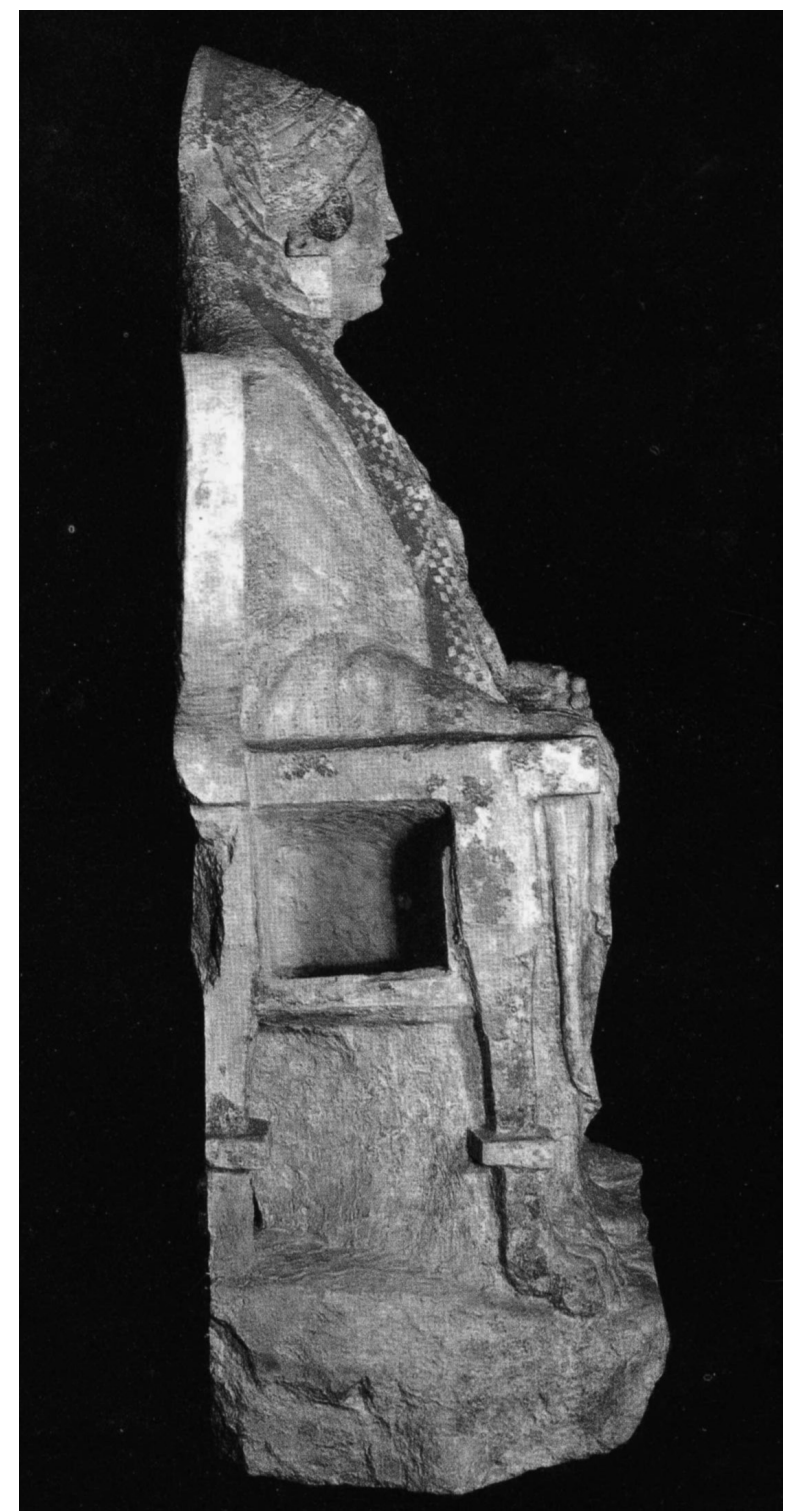

Figura 4: Aspecto lateral de la Dama de Baza.

es total y que además conserva el ennegrecimiento debido al depósito que contuvo; o con el busto de Baza que contiene un amplio vaciado cuya intencionalidad

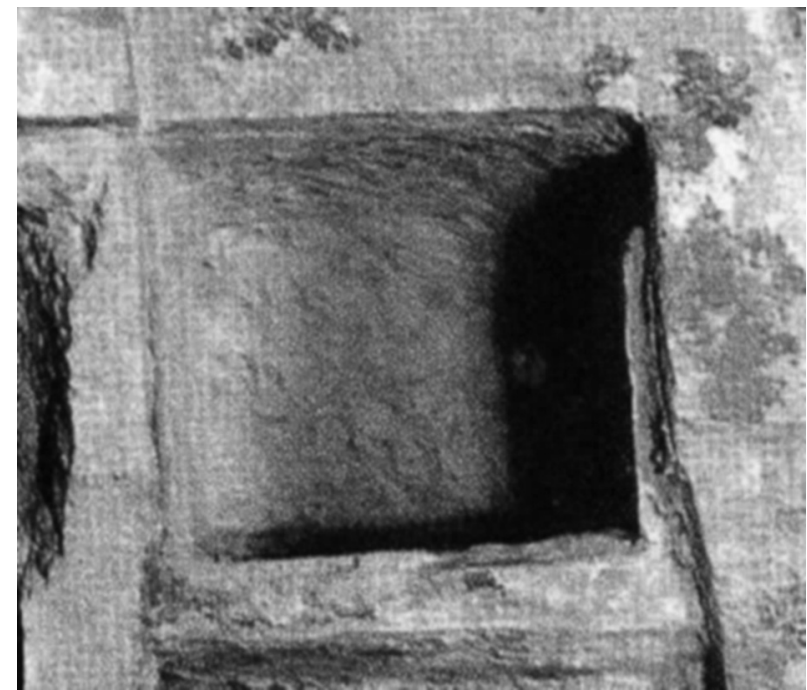

Figura 5: Detalle de la boca de acceso al vaciado de la Dama de Baza.

de amplitud de contenido fue tal que llegó a perforar la obra dada la delgadez de su zona anterior. Éste es un busto de piedra arenisca, policromado, descubierto en el llamado Cerro Largo de Baza, con orificio dorsal y vaciado interior parcial, que presenta la base alisada y que podría responder al tipo de forma escultórica contenedora de los restos de una cremación, a una estatua-urna, que también pudo ser la mitad superior de una pieza doble, pues «las entalladuras cuadrangulares que se marcan con claridad en la parte inferior de los cuatro ángulos laterales de la obra hacen pensar que la pieza se incrustó en algún soporte... un nuevo ejemplo de escultura antropomorfa resuelta como busto y, en algún momento, concebida como recipiente» (Chapa y Olmos, 1997, 163-170).

Además esta cavidad de la Dama de Elche, en el momento de su hallazgo, no ofrecía vestigios de utilización alguna y no presentaba ninguna huella del ennegrecimiento consecuente causado por las cenizas depositadas en el caso de haber sido empleada como urna funeraria, incluso si los restos de la cremación hubieran estado lavados.
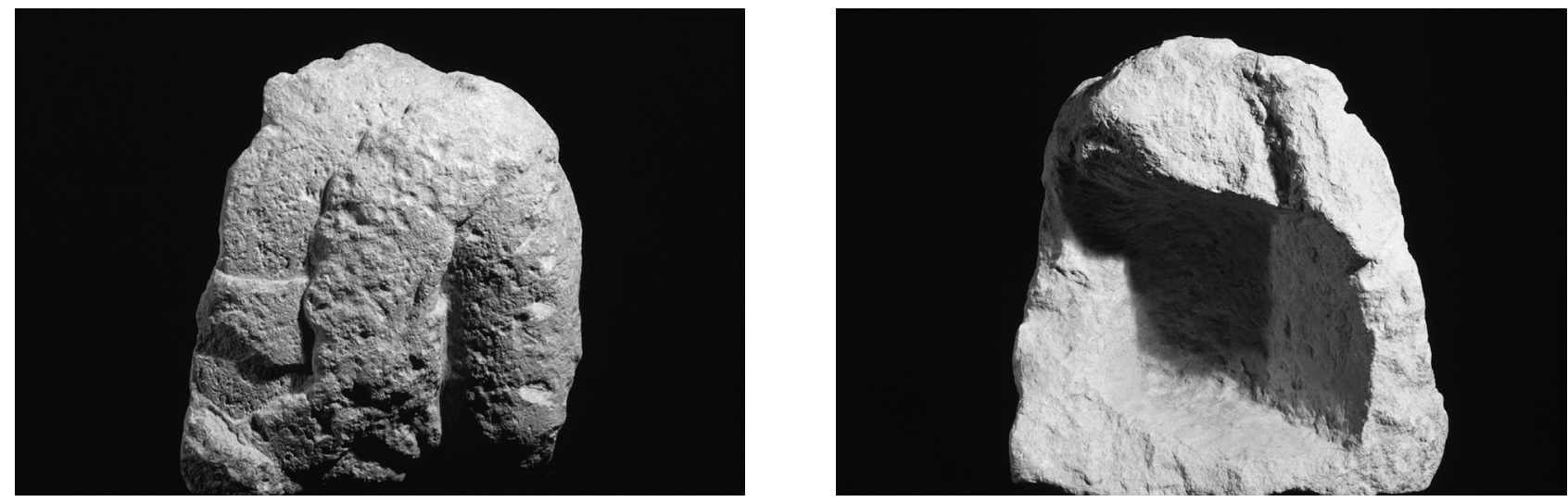

Figura 6: Fragmento de busto del Guerrero de el Parque de Elche y aspecto de su vaciado. 


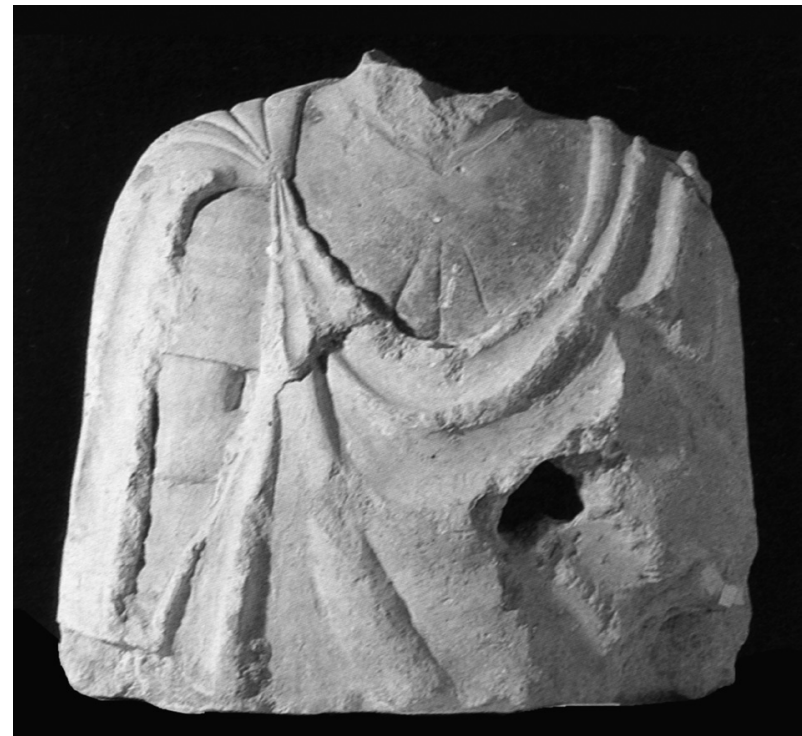

Figura 7: Busto de Baza.

A lo ya expuesto considero oportuno añadir el paralelismo funcional posiblemente existente entre el vaciado dorsal de la Dama de Elche y el de la Dama de Caudete (Soler, 1961, 165-168; 1976, 65-66; 1981, 22-24; 1993, 88-89; Ruano, 1987, 108-110), conservada en el Museo Arqueológico «José María Soler» de Villena, obra esculpida en piedra caliza, de sesenta y ocho centímetros de altura, que reproduce una imagen femenina en posición sedente (Fig. 8).

Fue descubierta en La Casita del Tío Alberto, yacimiento emplazado en las proximidades de la cuenca del río Vinalopó y por lo tanto relacionable con La Alcudia de Elche.

Su rostro, muy erosionado, sólo conserva el pulido de su acabado en una de sus mejillas pero, no obstante, permite la observación de unas facciones regulares y bien elaboradas. Va tocada con una tiara sujeta por una ancha diadema que detrás presenta una especie de timpanon o cubre-nuca alzada de remate paralelo al de la silueta de la tiara, cubierta por una mantilla que, en su nuca, se oculta bajo el manto que le cubre los hombros y los brazos, insinuando pliegues, que dejan ver sus manos apoyadas en las rodillas; a ambos lados del rostro muestra parte de los rizos de su peinado y luce sendas arracadas, gruesas, de tipo circular; sobre su pecho ostenta tres collares: el primero de ellos formado por tres grandes estuches de lengüeta entre los que se intercalan dos anforillas y los otros dos son de tipo acordonado; sus pies están totalmente cubiertos por el manto y su ausencia en la representación tal vez pueda aludir a que hubiera sido concebida con la apariencia de imagen incompleta, imagen en actitud de tránsito.

En la zona dorsal de su cuello, entre la mantilla y el reborde del manto, presenta una cavidad de forma semilunar con unas dimensiones interiores máximas
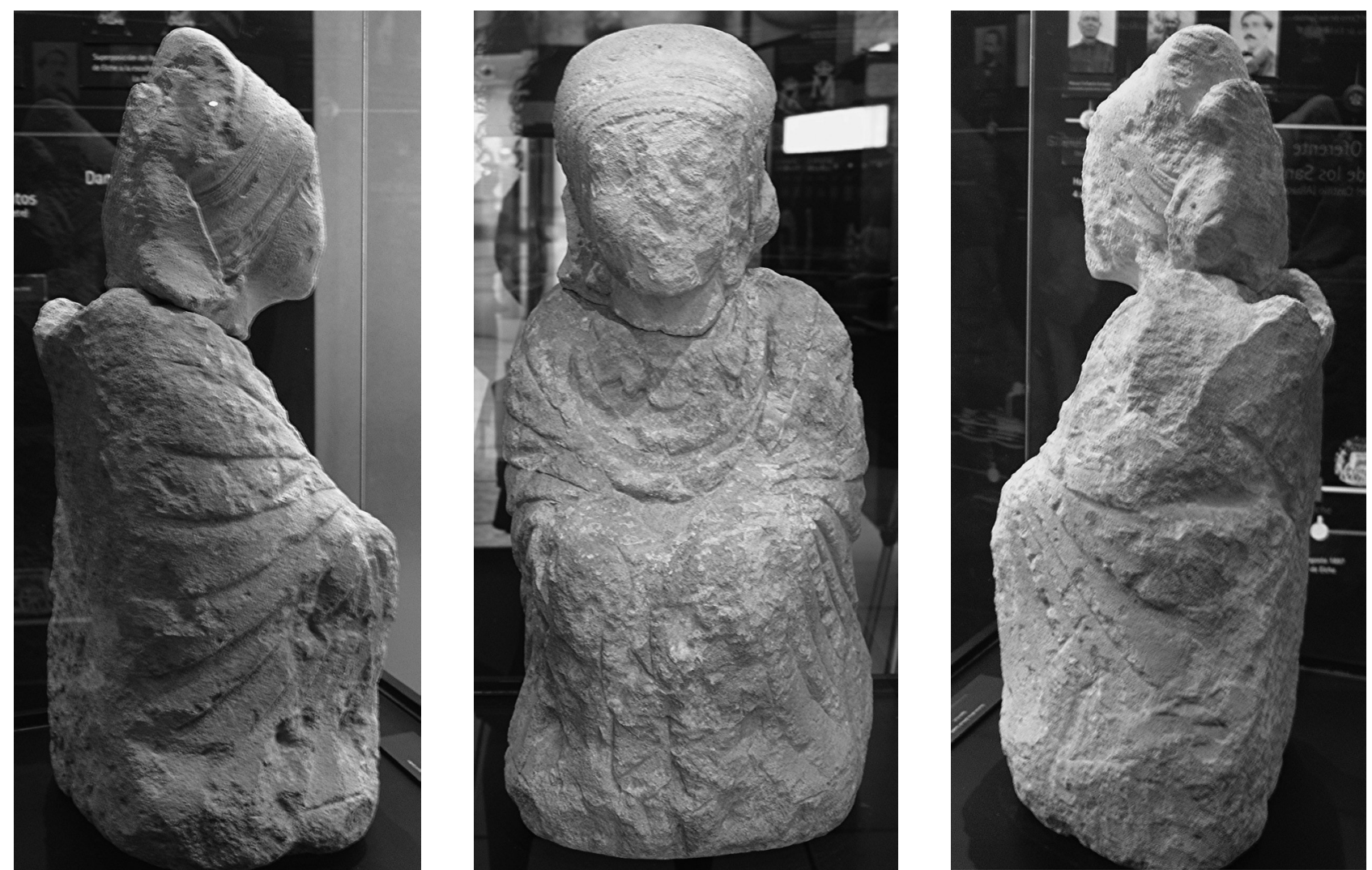

Figura 8: Dama de Caudete. 


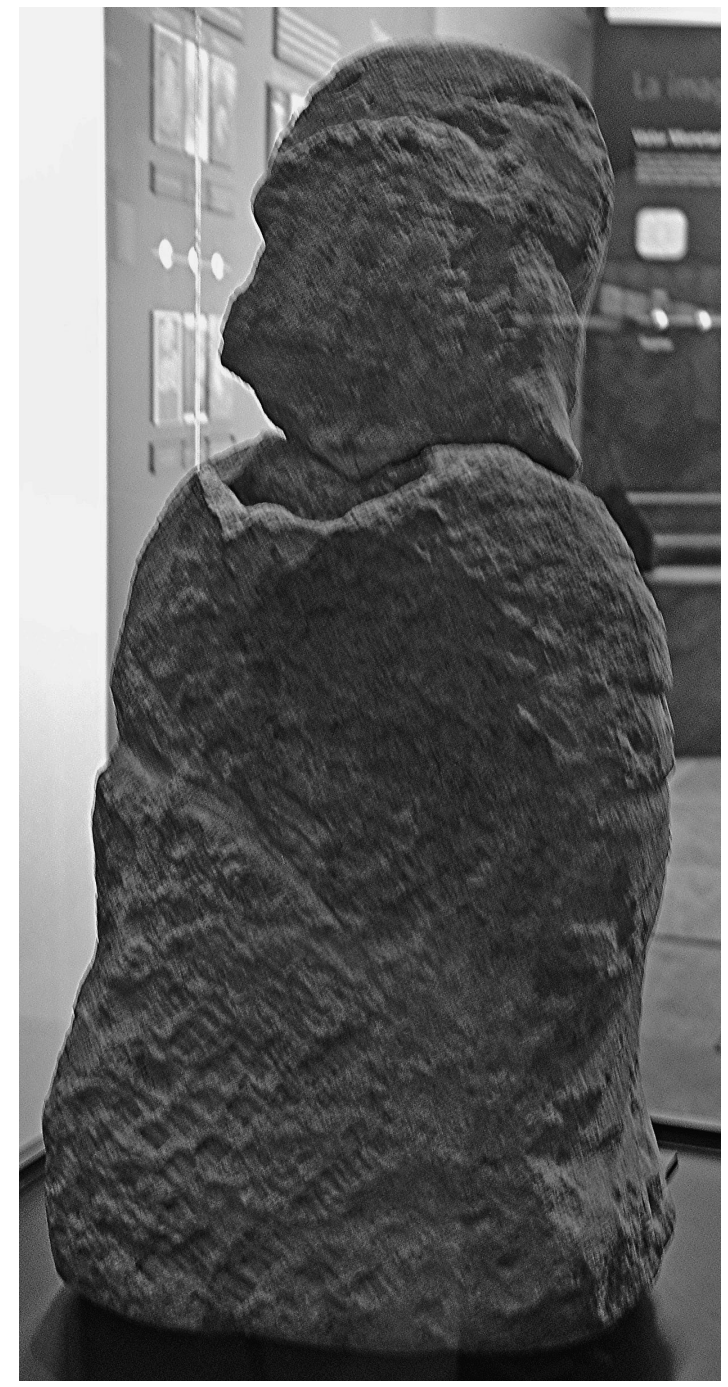

Figura 9: Aspecto dorsal de la Dama de Caudete.

de once centímetros de longitud, cuatro de anchura y cinco de profundidad. La reducida capacidad de esta cavidad $\left(220 \mathrm{~cm}^{3}\right)$ y el estado limpio que presenta sugieren que fuera realizado para desempeñar la función de depósito de alguna ofrenda o contenedor de alguna reliquia (Figs. 9 y 10).

Pero, aunque únicamente como argumento comparatista no probado, podría sumarse algo más a la ideología que pudo actuar para realizar las cavidades dorsales de las imágenes del mundo ibérico: la que originó a las que como contenedoras de objetos sagrados o venerables presentan ciertas representaciones momiformes egipcias de baja época ${ }^{1}$.

1. Deseo expresar mi agradecimiento a Luis Manuel Gonzálvez, Conservador del Museu Egipci de Barcelona, que, a efectos de documentar este trabajo, ha tenido la gentileza de colaborar en él con la aportación tanto de las fotografías del Ptah-Sócares-Osiris (E-206) del mencionado Museo como de la información relativa a las cavidades dorsales de las imágenes egipcias aquí recogidas.
En algunas imágenes de la cultura material faraónica se documenta la utilización de cavidades en determinadas partes de la figura realizadas para contener elementos de diversa índole. Son especialmente conocidas las denominadas estatuillas de la divinidad sincrética Ptah-Sócares-Osiris, obras de carácter funerario que fueron depositadas en las cámaras sepulcrales de tumbas privadas como un medio de garantizar la protección del cuerpo del difunto y, sobre todo, de propiciar su resurrección (Raven, 1980, 251-296). Obras que se utilizaron durante un espacio de tiempo comprendido entre la dinastía XXI y la época ptolomaica, período éste que ha proporcionado abundantes piezas $\mathrm{y}$ al que pertenece la aquí referenciada, que consiguientemente responde a una cronología relacionable con el período ibérico clásico.

Ptah fue un dios menfita patrón de los artesanos, considerado además dios creador por su relación con la artesanía, que fue llamado «el escultor de la tierra» pues él, en su torno de alfarero, lo había modelado todo. Por ello su sumo sacerdote llevaba el título de «gran guía de los artesanos». Este dios fue asimilado tanto al ctónico Tatjenen, para hacer surgir el dios creador Ptah-Tatjenen, como a Sócares (Sokar), divinidad de la necrópolis de Menfis, que tomó la forma de Ptah-Sócares-Osiris. Por lo que Ptah asumió, en función de estas asociaciones, los aspectos de estos dioses en sus facetas de divinidad creadora y funeraria al mismo tiempo que adoptó algunos de sus atributos como el úreo y el collar usekh, collar de oro de propiedades protectoras, llamado además «guirnalda de Atum», por tener nueve hileras que se vinculaban a la Eneada heliopolitana, y también «guirnalda de Khepri».

Sócares fue un dios menfita como Ptah que tuvo también carácter funerario como Osiris.

Sus representaciones egipcias se realizaron en esculturillas que reproducen cuerpos humanos de iconografía momiforme, de alturas comprendidas entre los cuarenta y los ochenta centímetros, tocados con una de las coronas específicas del dios. Están talladas en madera y se muestran siempre en pie, insertadas a una base.

Una de las peculiaridades de este tipo de estatuillas, aunque existen Ptah-Sócares-Osiris macizos, es

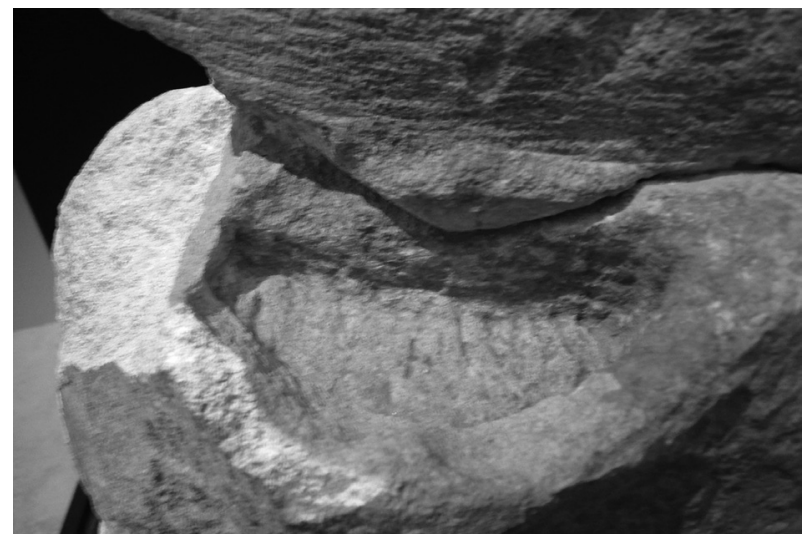

Figura 10: Detalle de la cavidad de la Dama de Caudete. 
la presencia de una cavidad en algún lugar de la pieza, que ocasionalmente puede localizarse en la base aunque lo habitual es encontrar la cavidad en el cuerpo de la figura, bien en el interior de una representación bivalva dividida verticalmente y ahuecada, o bien concretada en un vaciado parcial de la zona dorsal. En todos los casos lo que se evidencia es la clara intencionalidad de ocultación del hueco, cubierto con tapaderas, algunas de ellas todavía con restos de sellado.

En estas cavidades, como contenedores que fueron, se han localizado tanto rollos de papiro con textos del Libro de los Muertos como pequeños manuscritos, fibras de papiro y trozos de tejido, y también pequeñas figuras momiformes realizadas con una mezcla formada por barro y granos de cereal, vinculadas a las ideas de regeneración y de posibilidad de nueva vida. Son las denominadas corn mummies.

La figura del Ptah-Sócares-Osiris del Museu Egipci de Barcelona (E-206) (Fig.11) tiene una cavidad dorsal de ciento cinco milímetros de longitud, treinta $\mathrm{y}$ dos de anchura y veintiocho de profundidad, con una capacidad de $95 \mathrm{~cm}^{3}$, y su fotografía se muestra aquí como exponente de la idea de referencia del tipo de estatuillas aludido.
No obstante, además de existir en las figuras de Ptah-Sócares-Osiris, también se ha documentado la presencia de este tipo de cavidad en una estatua de madera de tamaño natural que representa a un faraón en pie y que fue utilizada como equipamiento funerario en una tumba real del Imperio Nuevo: Es la conservada en el Museo Británico signada como EA 882, escultura que muestra un vaciado de veinte centímetros de profundidad situado bajo la amplia proyección frontal de su falda y al que, aunque se desconoce su contenido original, se le ha atribuido la función de contenedor de papiros

Además, el hallazgo en La Alcudia de un escarabeo egiptizante (Ramos Folqués, 1950, 205; 1955, 306; Ramos Fernández, 1969, 37-43; 1974, 60) (Fig. 12) con la probable imagen del dios egipcio Ptah (Escolano, 2006, 73 y 75), cuyo culto se difundió por el entorno mediterráneo a partir del siglo $\mathrm{V}$ a.J.C, hace posible sugerir la posible relación ideológica entre las gentes que ocuparon este yacimiento en época ibérica y las corrientes religiosas egipcias llegadas a través del mundo fenicio (Fig. 13).

Este escarabeo está tallado en jaspe verde, tiene unas dimensiones de once milímetros de longitud,
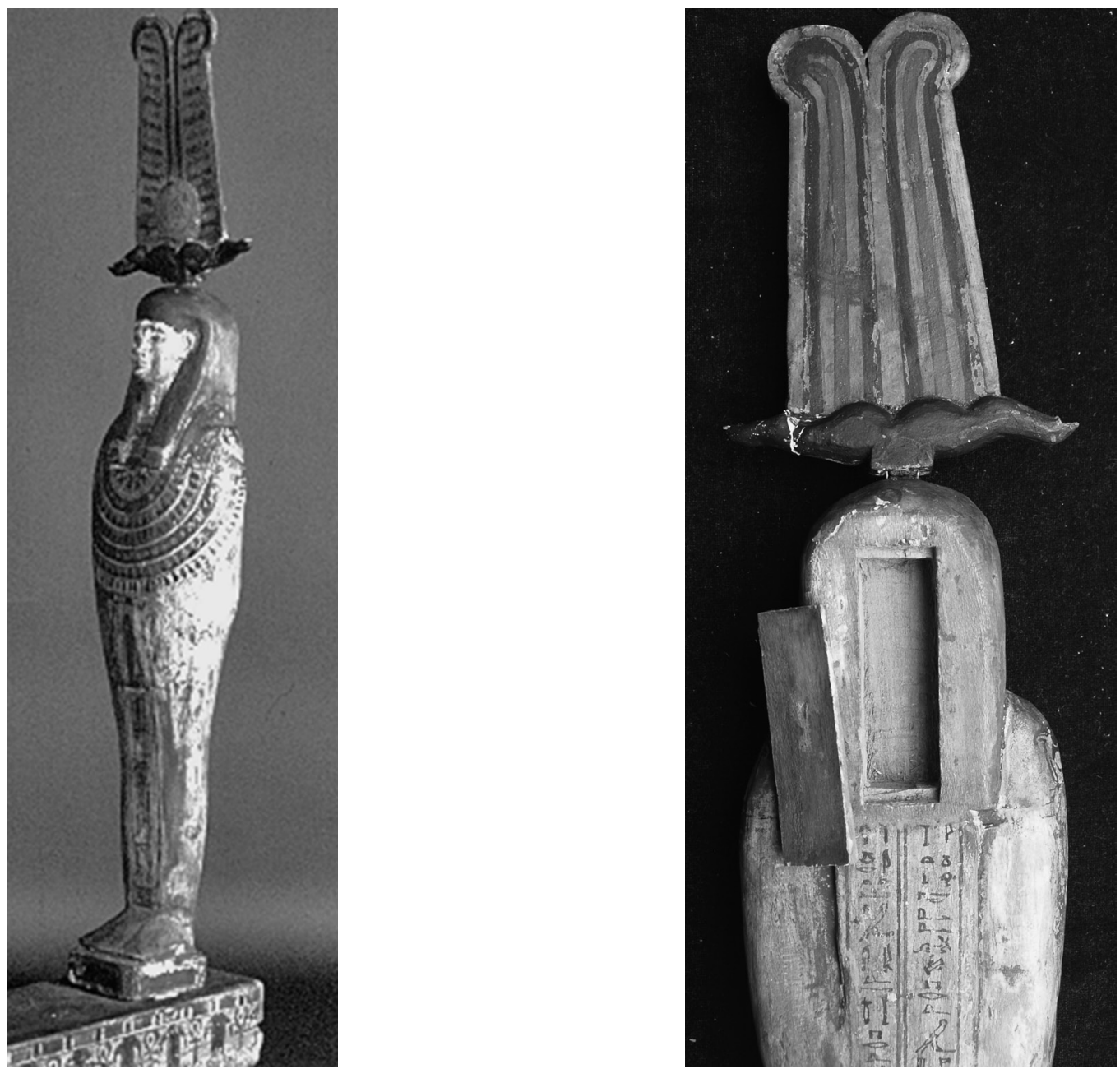

Figura 11: Aspecto general y detalle dorsal de la imagen de Ptah-Sócares-Osiris (E-206) del Museu Egipci de Barcelona. 

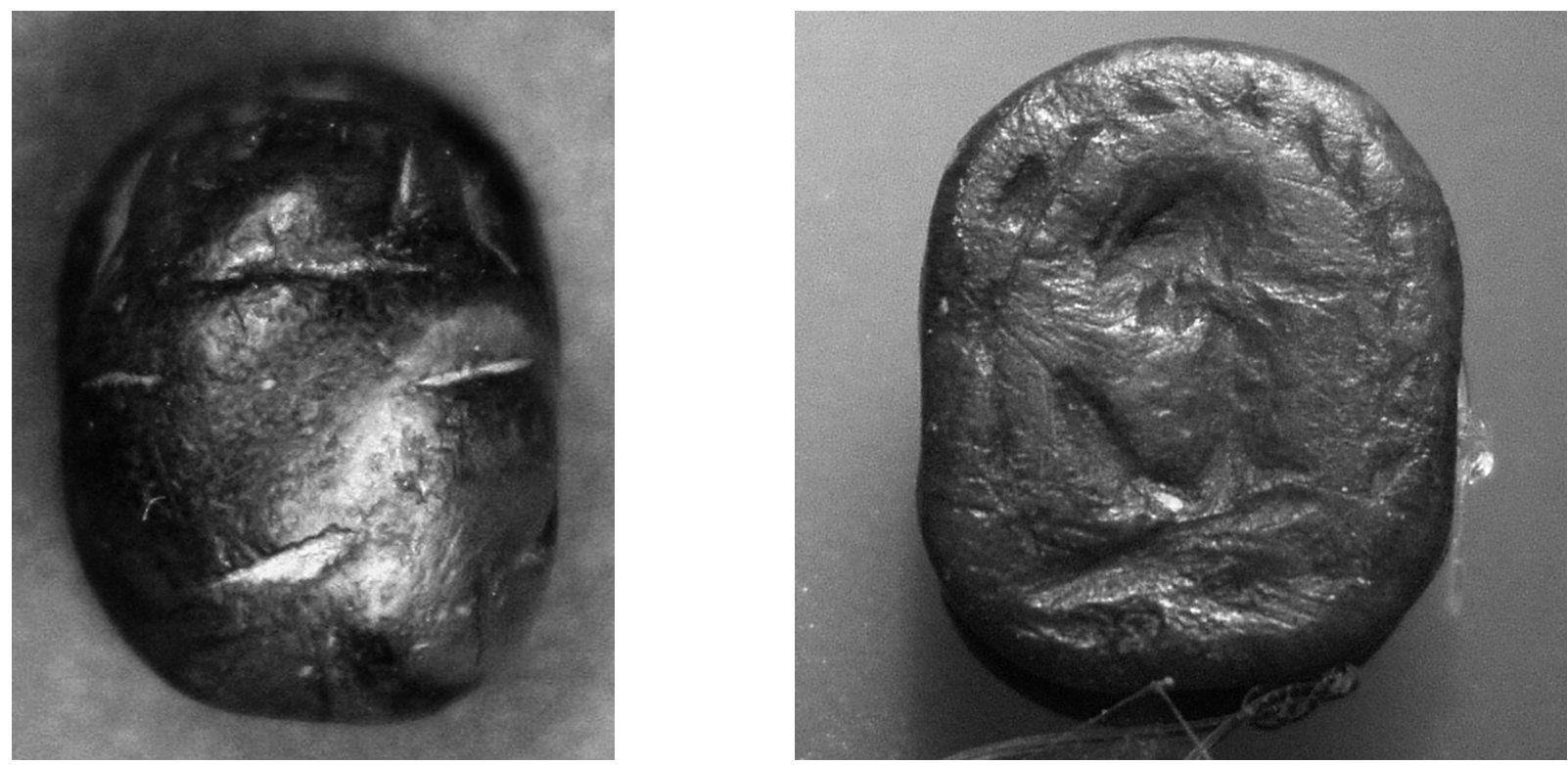

Figura 12: Aspectos dorsal y basal del escarabeo de la Alcudia de Elche.

nueve de anchura y siete de altura, está provisto de una perforación longitudinal de sección cilíndrica, muestra una representación dorsal con el protórax y los élitros bien marcados, sus patas están indicadas de forma esquemática y contiene un entalle en su base, rodeado por una orla pseudosogueada, que presenta una figura antropomorfa sentada cuya iconografía, en función de sus atributos, permite identificar al mencionado dios Ptah como artesano (Escolano, 2006, 73-75), sentado frente al trono y dando forma al huevo primordial. Está representado de perfil con la cabeza cubierta con un bonete esquematizado por una incisión vertical que se une a otra horizontal que la divide, con un úreo sobre la frente, marcado con una línea, con una prominencia de forma rectangular en la parte inferior de su rostro que alude a su barba recta y con el contrapeso del collar usekh, señalado por una línea curva que sale de la parte posterior de su cuello. Debajo de la imagen del dios parece distinguirse el signo del cesto con el interior rayado. Por el nivel arqueológico de su hallazgo (Ramos Folqués, 1955, 303) este escarabeo puede fecharse a partir del siglo IV a.J.C. y los estudios realizados sobre este tipo de objetos (Vercoutter, 1945, 344) informan que los escarabeos de pasta verde reemplazaron a los de pasta de importación egipcia a partir del siglo V a.J.C., que los escarabeos de jaspe verde con motivos egiptizantes pueden situarse cronológicamente entre los siglos V y IV a.J.C. y que su fabricación se debió a artesanos fenicios o púnicos sardos.

La idea de realizar una cavidad en ciertas obras escultóricas para ocultar algo en ella existió pues en Egipto y podría ser probable que aquella idea llegara a Iberia, posiblemente a través del comercio fenicio, y que a dicha finalidad de ocultación y custodia se dedicasen las cavidades dorsales de obras escultóricas ibéricas como la Dama de Caudete y la Dama de Elche, obras en las que estos contenedores, relativamente pequeños y limpios, no fueran lugar de depósito de los restos de la cremación de ningún difunto sino que pudieran aludir a la condición de poder guardar la reliquia, el talismán o el fetiche para los que fueron creados.

\author{
Dr. Rafael Ramos Fernández \\ Museo Arqueológico y de Historia \\ de Elche «Alejandro Ramos Folqués» \\ Palacio de Altamira \\ 03020 Elche
}

\section{BIBLIOGRAFÍA}

Bendala GalÁN, M., 1994: «Reflexiones sobre la Dama de Elche», Revista de Estudios Ibéricos, 1, 85-106.

Bendala Galán, M., 1996: «Una nueva hipótesis sobre la Dama de Elche», XXIII Congreso Nacional de Arqueología (Elche, 1995), vol. I, 299-304.

Bendala Galán, M., 1997: «Mirando a la Dama de Elche a la luz de la arqueología, la etnografía y la historia de las religiones», La Dama de Elche. Más allá del enigma, 143-156, Valencia

Bendala Galán, M. y BlÁNQuez PéRez, J., 1997: «Observaciones sobre la Dama de Elche», La Dama de Elche. Lecturas desde la diversidad, 133-144, Madrid.

BÉRARD C., 1974: Anodoi. Essai sur l'imagerie des pasajes chtoniens, Bibliotheca Helvetica Romana XIII, Neuchâtel.

Chapa, T y Olmos, R., 1997: «Busto de varón hallado en Baza», La Dama de Elche. Lecturas desde la diversidad, 163-170, Madrid.

Escolano PovedA, M., 2006: «El escarabeo egiptizante de La Alcudia», Lucentum, XXV, 71-76.

GONZÁLVEZ, L.M., 2007: Correspondencia manuscrita $(05 / 07 / 2007)$ en la que se informa del Ptah-SócaresOsiris (E-206) del Museu Egipci de Barcelona y de la 
investigación arqueológica referida a él y a las cavidades dorsales en obras escultóricas egipcias.

HÜBNER, E., 1898: «Die Büste von Illici», Jahrbuch des Archaeologischen Instituts, XIII, 114-134.

IBARRA RUIZ, P., 1897: «Hallazgo en Ilici»,La Correspondencia Alicantina, 7 de agosto; Las Provincias, Valencia, 19 de agosto; La Ilustración Española y Americana, $\mathrm{n}^{\circ} 32,30$ de agosto; El Siglo XX; y L'Ilustration, $\mathrm{n}^{\circ} 2849,2$ de octubre.

IBARRA RUIZ, P., 1903: «Conclusiones sobre la Dama de Elche», Revista de Arquitectura y Construcción, Barcelona.

IBARRA RUIZ, P., 1926: Elche. Materiales para su historia, Cuenca (incluye información epistolar referida a las opiniones de Saavedra y Rada y Delgado).

LUXÁN, M.P., PradA, J.L. y DORREGO, F., 2005: «Dama de Elche. Pigments, surface coating and stone sculture», en Materials and Structure, RILEM Paper, 38: 277, 419-424.

MÉLIDA, J.R., 1897: «Busto ante-romano descubierto en Elche», Boletín de la Real Academia de la Historia, XXXI, 427.

MÉLIDA, J.R., 1897: «Busto ante-romano descubierto en Elche», Revista de Archivos, Bibliotecas y Museos, 440-445.

MÉLIDA, J.R., 1898: «Busto ante-romano descubierto en Elche», Revista de la Asociación Artístico-Arqueológica Barcelonesa, I, Barcelona.

PARIS, P., 1898: «Buste espagnol de style gréco-asiatique trouvé a Elche», Monuments et Memoires, IV-2, $1-32$, Fondation Piot, París.

Presedo Velo, J., 1973: La Dama de Baza, Museo Arqueológico Nacional, Madrid.

RAMOS FERNÁNDEZ, R., 1969: «Amuletos de tipo púnico descubiertos en La Alcudia (Elche)», Revista del Instituto de Estudios Alicantinos, 2, 37-47.

RAMOS FERnÁndeZ, R., 1974: De Heliké a Ilici, Guías Artísticas Provinciales 1, Alicante.

RAMOS FERNÁNDEZ, R., 1987a: «La escultura antropomorfa de Elche», Escultura ibérica en Revista de Arqueología, 94-105.
RAMOS FERNÁNDEZ, R., 1987b: «Demarcación ibérica en el Parque de Elche», XVIII Congreso Nacional de Arqueología (Islas Canarias, 1985), 681-699, Zaragoza.

RAMOS FERNÁNDEZ, R., 1990: «Obras arcaicas de escultura ibérica en el Museo Arqueológico de Elche», Boletín de la Asociación Española de Amigos de la Arqueología, 28, 26-34.

RAMOS FernÁndeZ, R., 1991: «La Dama de Elche», $M a-$ drid, 4, 116-119.

RAMOS FernÁndez, R., 2003: Documentos y reflexiones sobre una Dama, Elche.

R. RAMOS FERNÁNDEZ y RAMOS MOLINA, A., 1992: El monumento y el témenos ibéricos de El Parque de Elche, Serie Gran 2, Elche.

RAMOS FolQUÉS, A., 1950: «La Alcudia de Elche, antes y durante la dominación púnica», I Congreso Nacional de Arqueología y V Congreso Arqueológico del Sudeste Español (Almería,1949), 204-208, Cartagena.

RAMOS FOLQUÉS, A., 1955: «Vestigios cartagineses en La Alcudia de Elche», I Congreso Arqueológico del Marruecos Español (Tetuán, 1953), 303-307, Tetuán.

RAVEN, M.J., 1980: «Papyrus-Sheaths and Ptah-SokarOsiris Statues», Oudheidkundige mededeelingen, 49-50 (1978-1979), 251-296.

REVERTE COMA, J.M., 1986: «Informe antropológico y paleoantropológico de los restos cremados de la Dama de Baza», Coloquio sobre el Puteal de la Moncloa, 187192, Madrid.

RUANO RUIZ, E., 1987: La escultura humana en piedra en el mundo ibérico, Madrid.

SOLER GARCÍA, J.M., 1961: «Cabeza escultórica del Museo Arqueológico de Villena», Archivo Español de Arqueología, XXXIV: 103 y 104, 165-168.

SOLER GARCÍA, J.M., 1976: Villena: prehistoria-historiamonumentos, 65-66, Alicante.

Soler GARcíA, J.M., 1981: «La Dama de Caudete», Historia de Villena, 22-24, Villena.

SOLER GARCíA, J.M., 1993: «La Dama de Caudete», Guía de los yacimientos y del Museo de Villena, 88-89, Valencia.

VerCOUTTER, J., 1945: Les objets égyptiens et égyptisants du mobilier funéraire carthaginois, París. 